\title{
NOCTURNAL FLOW ON A WESTERN COLORADO SLOPE*
}

\author{
John M. Leone, Jr. and Paul Z. Gudiken \\ Lawrence Livermore National Laboratory \\ Box 808, Livermore, California 94550
}

\section{INTRODUCTION}

The Department of Energy sponeored Atmonpheric Studies in Complex Terrain (ASCOT) program has conducted a rewearch program deaigned to increase our knowledge and understanding of terrain-dominated flow with specific emphasis on nocturnal flows within mountain valleys. ASCOT has sponeored both field studies and numerical modeling efforts to improve our underatanding of the wind, temperature and turbulence atructure of nocturnal drainage tlown. One of the mont recent ASCOT sponsored field studiet inrolves a study within the Mess Creek Basin in western Colorado to investigate the reanonal frequency of occurrence of drainage flow a along the sloped surfacen and within the besin, and to evaluate the effect of the ambient meteorology on their derelopment.

The Mesa Creek Basin, aituated on the north sope of the Grand Mesa, encompasses a roighly $10 \times 20 \mathrm{~km}$ aren that is approximntely $30 \mathrm{~km}$ east of Grand Junction. The observational segment of the atudy was undertaken jointly by the Lawrence Livermore National Laboratory and the NOAA Wave Propagation Laboratory, and involved the operation of a netwurk of eight meteorological towers and a monostatic sodar within the Mess Creek study area orer a period of one year that extended from December 1988 through November 1988. These measurements rere augmented by tethersonde observations to define the rertical wind and temperature structure during a few nights. The prelimizary sesults of the field studg will be reported in King, Gudiksen, and Ruscell (1900). The modeling portion of the study is being undertaken by Lawrence Livermore Laboratory using a three-dimensional prognostic boundary layer model to gain further insight into the dyamics of the seasonal variations and the effect of cloud cover on the development of the drainege flows. It is the purpose of this paper to present preliminary results from a numerical simulation done as part of this study.

*Work performed under the auspices of the U.S. Department of Energy by the Lamrence Livermore National Laboratory uader contract No. W7405-Eng-48. 


\section{THE MODEL}

The model used for the simulations reported here solves the 3-dimenaional, nonbydrostatic, Boussinesq equations of motion shown balow.

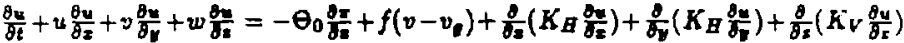

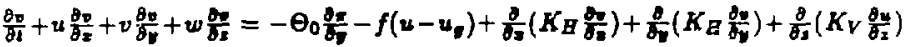

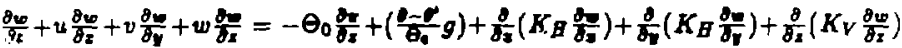

$$
\begin{aligned}
& \frac{\partial u}{\partial z}+\frac{\partial}{\partial y}+\frac{\partial_{w}}{\partial x}=0 \\
& \frac{\partial \theta}{\partial t}+u \frac{\partial \theta}{\partial z}+v \frac{\partial \theta}{\partial y}+w \frac{\partial \theta}{\partial z}=\frac{\theta}{\partial z}\left(K_{B} \frac{\partial \rho}{\partial z}\right)+\frac{\partial}{\partial y}\left(K_{B} \frac{\partial \theta}{\partial z}\right)+\frac{\theta}{\partial z}\left(K_{V} \frac{\partial \theta}{\partial z}\right)
\end{aligned}
$$

where the usual meteorological notation has been used with $u, \nabla, w$ are the $x, y, z$ components of the velocity respectively; is the deriation potential iemperature, and is the deviation Exner function. The constants $f, g, u_{s}$, and $v_{g}$ are the Coriolis parameter, the gravitational acceleration, and the $x$ and $y$ components if the large scale geostropbic wind, reapectively. The equations have been linearized about a motionless bydrostatic basic atate defined by:

$$
\begin{aligned}
& \Theta(z, y, x, t)=\Theta_{0}+\theta(x, y, z, t) \\
& \Pi(z, y, z, t)=\Pi_{0}(z)+\pi^{\prime}(z)+\pi(x, y, z, t)
\end{aligned}
$$

where $\frac{\partial \Pi_{x}}{\partial x}=\phi_{0}$ and $\frac{\partial x^{\prime}}{\partial x}=g \frac{\theta^{\prime}}{\partial y}$

with $\theta^{\prime}(z)$ a horizontally averaged potentiel temperature.

To close the system of equation, we must define the turbulent diffusivities, in and $\mathrm{K}_{V}$. For the simulations reported herein, the horizontal edd 5 diffusivity bas been taken to be constant with a value of $100 \mathrm{~m}^{2} / \mathrm{m}$, while the rertical difiusivity, $\mathrm{K}_{V}$, was modeled using a parameterization developed by MeNider and Pielke (1981).

The spatial discretization of the equations is accomplished vis the finite element method using tri-linear basis functiona for the velocity components and the ternp: $r$ ature and piecewise constant basis function for the prebure. For efficiency, mass lumping and 1 point quadrature were employed. The time integration scheme is a variant of the forward Euler acheme. The forward beckward scheme of Sun (1980) is used on the buogancy term, and the edrection terms are atebilized via the iroplementation of the balancing tensor diffusivity. (The model in described in detail in Leone and Lee, 1989.) 


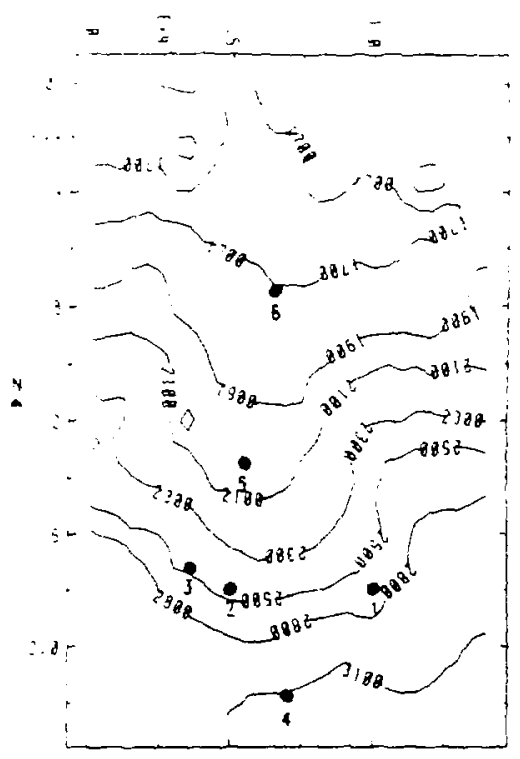

Figure 1. The topography within the computational dorain, contours every $200 \mathrm{~m}$. Also shown are the locations of 8 of the abservational towers.

\section{THE SITE}

The topographic features of the Mess Creek drainage basin resolved within the modeled terrain and the location of six of the meteorological towers are shorn in Fig. 1. The study area is bounded on the south and west aides by the Grand Mesn, a ridge on the east side and the Plateau Valley toward the north. The terrain varies in height from $3200 \mathrm{~m}$ on the Grand Mesa to about $1500 \mathrm{~m}$ within the bosin. The slope geperated flows drain into the basin where they merge with those generated within the Plateau valley whose drainage aren ia largely ajtuated east of the atud $z$ area. The flows within the Plateau Valley subsequently drain westwand into the Colorado River drainage ares.

\section{THE SIMULATION}

The horizontal domain used for the simulations reported here is the ares shown in Fig. 1 and encompassed a distance of $14 \mathrm{~km}$ in the crass basin direction and 22.5 $k$ in in the dowa basin direction. The top of the domain was taken to be at 4500 metera above mean gea level giring a vertical domain size of 1469 meters above the highest point and 2976 meters above the lowest point. The domain was divided into 
twenty-eight (28) $500 \mathrm{~m}$ long elements in the crose bain direction, thirty (30) $750 \mathrm{~m}$ long elements in the down basin direction, and sixteen (16) elements in the vertical direction which were $7.5 \mathrm{~m}$ high at the ground and increased in size toward the top of the domain.

The simulation reported here was for a simple undisturbed nocturnal flow development. The large scale geostrophic wind was ssumed to be zero as was the initial velocity field. The initial potential temperature field was alightly stable, with a vertical gradient of $1 \mathrm{~K} / \mathrm{km}$, and horizontally uniform. The drivigg force was a surface hest fiux of $-40 \mathrm{Wm}^{-2}$ applied uniformly on the domain for 1 period of two bours. The velocity boundary conditione were the no-alip condition on the surface and at the top of the domain the relocity wae set equal to the large acale geostrophic wind (zero in this case). The lateral boundary conditions were:

$$
\begin{aligned}
& f_{n}=-\pi+K_{B} \frac{\partial_{n}}{\partial x_{0}}=0.0 ; \\
& f_{n}=K_{n} \frac{\partial u_{n}}{\partial x_{n}}=0.0 ; \quad f_{n}=K_{n} \frac{m_{n}}{\partial n_{n}}=0.0 ; \\
& \frac{\partial \theta}{\partial z_{0}}=0.0 \text { where } n \rightarrow \text { vormal and } \tau_{i} \rightarrow \text { the ith tangent to in: boundary. }
\end{aligned}
$$

\section{THE RESULTS}

The results presented here will be for a simulated time of 2 hours. While the details of the flow were not at steady state, the main features were well eatablished and steady. Also, it was felt that continuing the simulation with a constant surface heetflux as a forcing would be unrealiotic. Figure 2 is a snaphot of the flow at 7.5 meters above ground level (AGL) after two bours of cooling. Three distinct drainage regions can be seen; one originating on the southeast rim of the basin, a second coming from the center of the mesa, and the third flowing off the west wall of the basin. These merge into a single down basin flow through the center of the basin.

Figure 3 presents a series of cross-basin vertical cross sections of the northerly velocity component. Figure 3a, located on the upper slope (arrow 1 in Fig. 2), shows a significant down-basin flow acroas 3/4'a of the bavin with two distinct centers representing the northeast corner flow and the central flow. The maximum down-basin speed is $2.9 \mathrm{~m} / \mathrm{s}$ within the central flow. Fig. $3 b$, half $r a y$ down the basin (arrow 2 in Fig. 2), shows a continuation of this patiern. However, the central flow is now clearly dominant with the maximum speed increasing to $3.4 \mathrm{~m} / \mathrm{s}$. Figure ic, just before the entrance to the Plateau River Valley (arrow 3 in Fig. 2), show a single strong core flow with a maximum speed of $3.1 \mathrm{~m} / \mathrm{s}$. The flow in seen to be rertically confined to a shallow layer. Figure 3d, within the Plateau River Valley (arrow 4 in Fig. 2), shows a significantly altered pattern. Here the maximum speed in the northerly direction is only $2.5 \mathrm{~m} / \mathrm{s}$ and the height of the jet core has elevated aignificantly. We believe that this anomaly is a numerical artifact of two weaknesses in the simulation. The first is the lack of significant terrain within the model domain north of the Plateau River Valley, and the second is the inability of the model to reproduce the flow down the Plateau River Valley due to upstream influences. Each of these contribute to the lack of turning of the local flow into and down the Plateau River Basin. We believe however, that these effecta are very local and do not aignificantly perturb the solution on the basin slopes. 


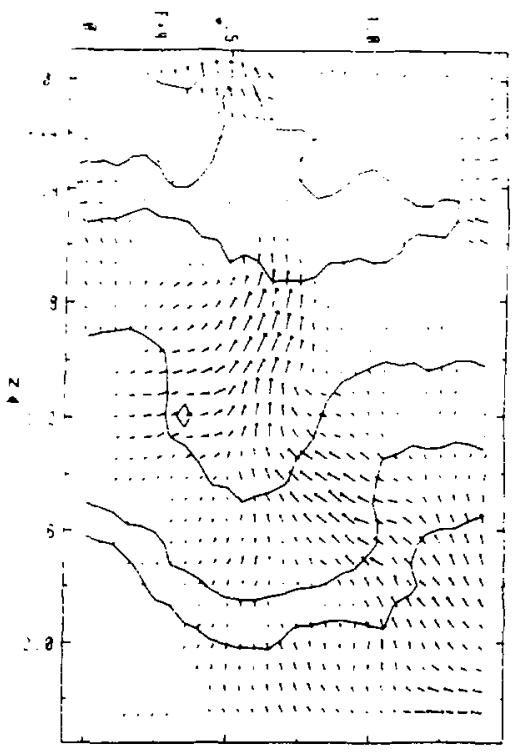

Figure 2. The horizontal wind field after 2 hour of cooling at $7.5 \mathrm{~m}$ AGL. Terrain contours every $400 \mathrm{~m}$ are provided for reference. The numbered arrow on the left side of the figure indicate the positions of the rextisal crose sections presented in Fig. 3.

As a further aid in underatanding the atructure of the flow and the reprasentativeness of the observation sites, we examined the flow in more detail at the six tower locations marked on Fig. 1. Sites 1, 2, and 3 represent an acroas basin section, while sites 4,5 , and 6 depict a down basin mection. The rertical proflea of down alope winds across the basin are plotted in Fig. 4. Site 1 which is in the southeant rim flow and site 2 which is in the central How are seen to be rery similar in both speed and vertical structure. Site 3 which is between the central flow and the weat wall fow is significantly weaker and shallower. These results seem to indicate that the difference is caused by the character of the upwind terrain. Site 3 is down wind of a relatively flat region that does not eppear to drain w readily as the more sloped regions upwind of the other two sited. In contrant, the rertical temperature change profiles shown in Fig. 5 for the same aite show a more uniform change with the eastern site having cuoled the moat, the weatern site cooling the least, and the central site midway betwzen.

The down basin variation of the vertical profiles of dewnslope winds is presented in Fig. 6 using sites 4 on the mess top, 5 about half $w a y$ down the basin, and 6 near the entrance to the Plateau River Valley. The flow on the mesa top is weak and relatively shallow. The flow at aite 5 is seen to be deeper than on the mesa top, but only very slightly stronger. The slow speed is a function of the site's position just to the west of the core of the How which has a marimum speed of $3.4 \mathrm{~m} / \mathrm{s}$. This 

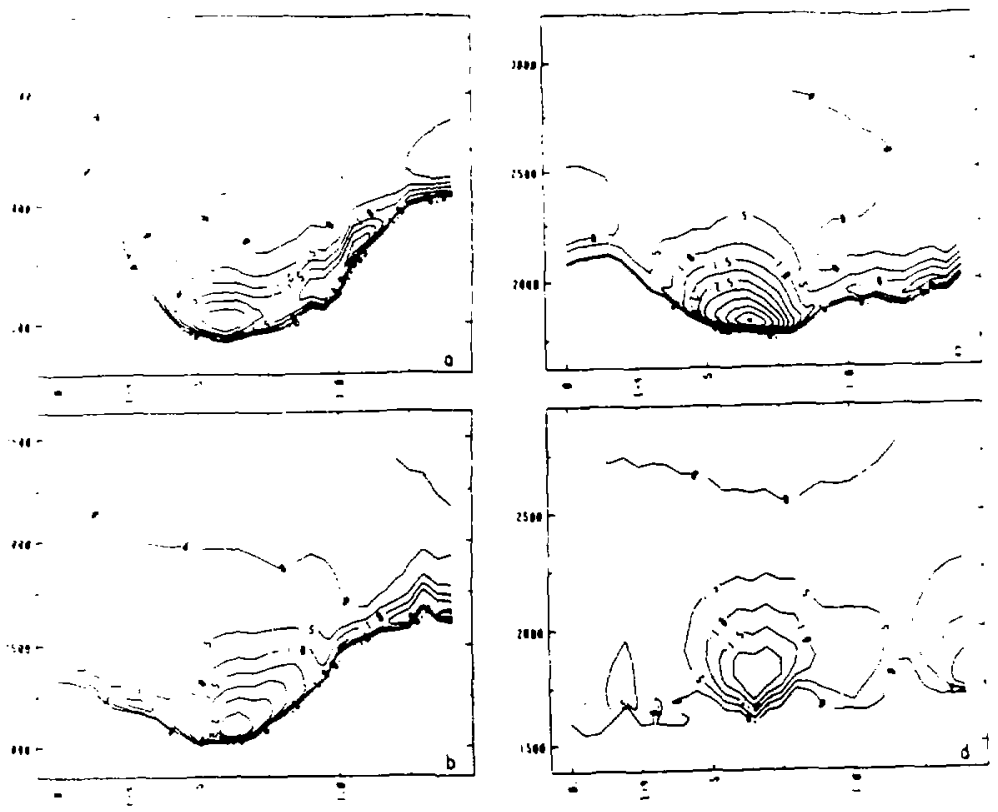

Figure 3 . Vertical crose sections of the northerly component of the wind at the 4 locations marked in Fig. 2. The contour interval $0.5 \mathrm{~m} / \mathrm{m}$. a) is along the slope (arrow 1 in Fig. 2) b) is in the middle of the basin (arrow 2 in Fig. 2) c) in near the entrance to the Platesu River Valley (arrow 3 in Fig. 2) d) is in the Plateau River Valleg.

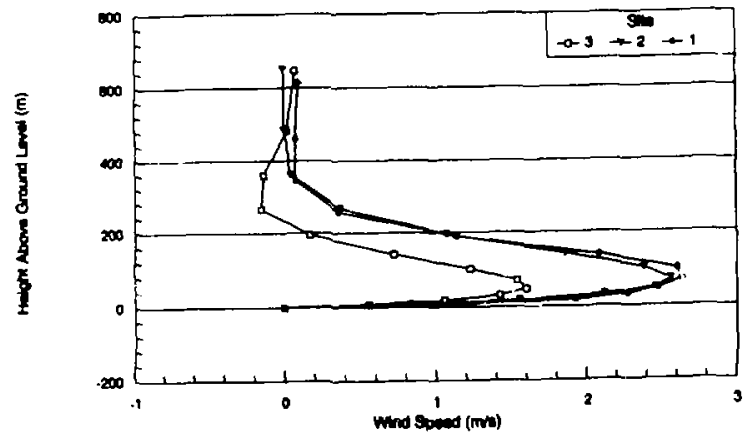

Figure 4. Vertical profiles of downclope velocity after two houra of conling at the sites marked as 1, 2, and 3 in Fig. 1. 


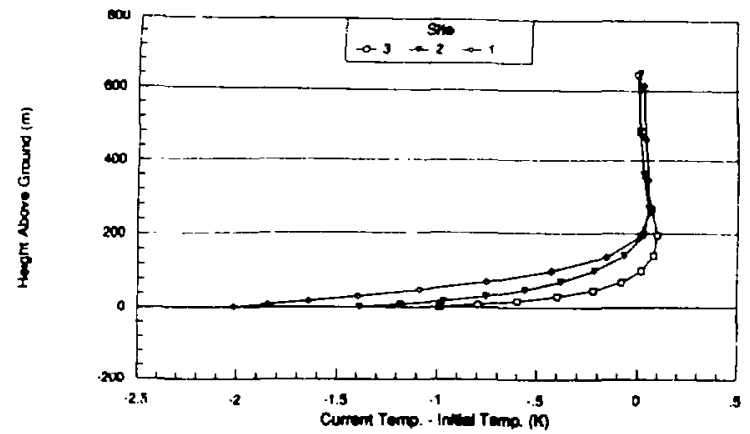

Figure 5. Vertical profiles of the total temperature change over two houre at the sites marked as 1, 2, and 3 in Fig. 1.

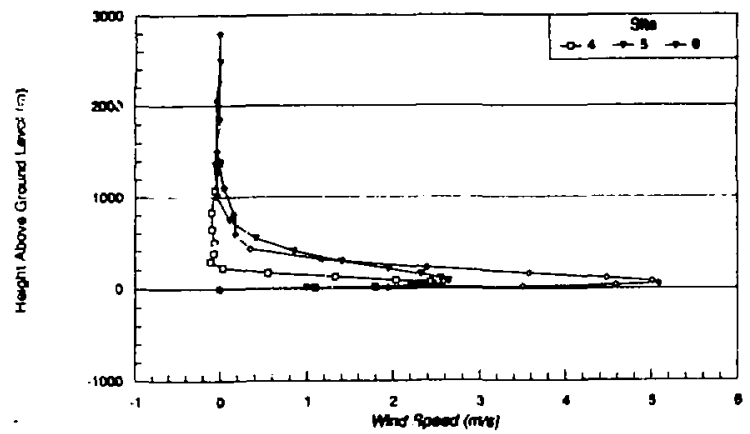

Figure 6. Vertical profiles of downslope velocity after two hours of cooling at the sites marked as 4,5 , and 6 in Fig. 1.

suggests that the tower data may undereatimata the speed of the drainage flow at mid-basin. The flow at aite $B$ is significantly faster than at the other two sites but the flow depth is approximately the same as at site 5 indicating that the drainage flow depth is not strietly a function of mass flux but also a strong function of thermal structure which is shown in Fig. 7. As expected, the maximur cooling has taken place at site 6 at the foot of the basin and the least has taken place at site 4 on the mesa top. The depth of the cooling reaches a maximum at epproximately site 5 and is constant down to the fook of the baxin. 


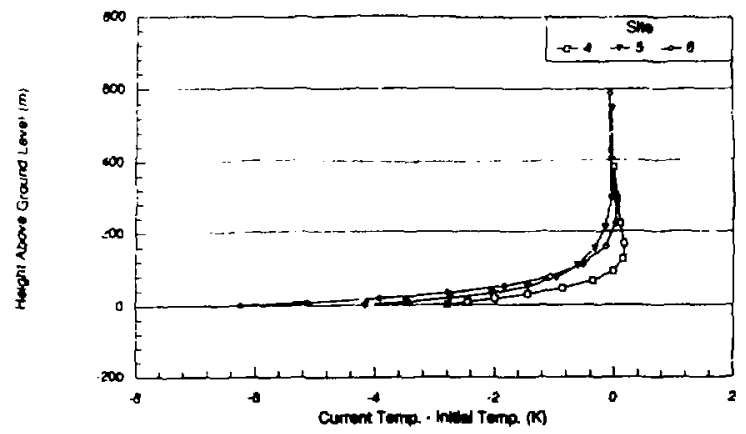

Figure 7. Vertical profiles of the total temperature change over two houra at the sites marked as 4,5 , and 8 in Fig. 1.

\section{DISCUSSION}

While a comprehensive comparison with data is not jet possible, we surveyed some preliminary observations to gain innight into the performance of the model. Because the night for which date were arailable had a non-zero gecotrophir wind tather than the assumed calm conditions, the comparison must be treated as indicative rather then abeolute. The results of the comparien demoratrated that the model is qualitatively correct except within the Plateau River Valley. Further, there are indications that the model results may be correct in some details. For example, the observations show that wite 3 had the reakent drainage flow of the crou basin sites with an observed difference from the flow at site 3 of appraximately $0.9 \mathrm{~m} / \mathrm{s}$. This is remarkably similar to the model result of a difference of $1.0 \mathrm{~m} / \mathrm{o}$. Also, the dowaslope wind speed at site 2 was observed to be $3.2 \mathrm{~m} / \mathrm{s}$ which is very similar to the $2.6 \mathrm{~m} / \mathrm{s}$ wind produced by the model. However, not all comparisons were as favorable. The model did not produce a significant difierence between sites 1 and 2 while the observations showed that aite $3 \mathrm{mas} 2 \mathrm{~m} / \mathrm{s}$ atronger than at aite 2 . The model seems to orerpredict the depth of the drainage flow by a factor of 2 or more. While the available dara nere not sufficient to determire if the model was correct in predictiog that site 5 would be located east of the drainage flow maximum, the obserntion that the flow at site 1 was atronger than at aite 4 could imply that the model was correct. In order to determine exactly how much of the agreement is serendipitous, we will have to wait until the full data set is available.

As the data become arailable, we plan to make in depth comparions with the model results with the two-fold objective of improving the modeling capabilities and increasing our understanding of the phenomena lurking behind the relatively aparse data. We believe that a cooperative exchange between modeling and observational efforts will yield the maximum benefit for the study of terrain driven flows. 


\section{REFERENCES:}

KinB, C. W., P. H. Gudiken, and C. A. Russell (1990): "Sodat-Derived Noctur" ad Drainage Flow Clanifications," to be presented at the Firth Conference on Mountain Meteorology, Boulder, Colorado, June 25-20, 198.?.

Leone, J.M., Jr. and R.L. Lee (1889): "Numerical Simulation of Drainag- Flow in Brush Creek, Colorado," J. Appl. Met. 28, po 530-542.

McNider, R.T. and R.A. Pielke (1981): "Diurnel joundary Lajer Dejelopment Over Sloping Terrain," J. Atmos. Sci., 3B, pp 2198-2212.

Sun, W. (1980): "A Formard-Bachward Time Integration Scheme to Treat Lnternal Gravity Waves," Mon. Wea. Reo., 108, Pp 402-407. 


\section{DSCO. IISHR}

I his dorument has prepared as un acecuat of uark aponsered b: an apensy of the

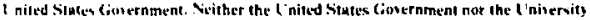

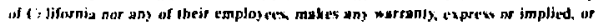

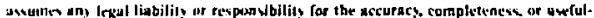

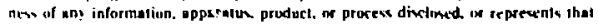
II) uss would not infrings pritatel) nuned rights. Reference hertin to any specific cummercisl produrts procesw or servior by Irade natre, tradematk, manulacturus, or whernise. deses nol nerewasily ronstitule os imply is endatwerent, tecomenendation. of fasoring b) the I nited biates Consernment or the I niversit) of ('alifornim, The 14. hise of the I nited Sigates Goterament of the (Intrersity of ('uliforning und shall not

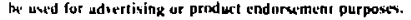

